\title{
Comparison of dissolution profile of extended-release oral dosage forms - Two one-sided equivalence test
}

\author{
Felipe Rebello Lourenço*, Daniela Dal Molim Ghisleni, Rosa Noriko Yamamoto, \\ Terezinha de Jesus Andreoli Pinto
}

Department of Pharmacy, Faculty of Pharmaceutical Sciences, University of São Paulo

\begin{abstract}
The aim of this work is to present the two one-sided test (TOST) as an alternative approach to compare dissolution profiles of extended-release dosage forms. The dissolution profiles of oxycodone extendedrelease tablets containing $10 \mathrm{mg}, 20 \mathrm{mg}$ and $40 \mathrm{mg}$ (reference and generic) were evaluated according to the requirements described in United States Pharmacopeia. These dissolution profiles were compared using the conventional similarity factor (f2) and the proposed TOST as an equivalence test. TOST is a simple and alternative approach to compare dissolution profiles of extended-release dosage forms. It allows us to identify the time-point (or time-points) that did not show similarity. We concluded that the two one-sided test performed at a significance level of $5 \%$ and defined as $\Delta=10$ showed results comparable to those obtained by the conventional similarity factor (f2).
\end{abstract}

Uniterms: Dissolution profile. Extended-release tablets. Similarity factor. Two one-sided test. Equivalence test.

O objetivo deste trabalho é apresentar o teste uni-caudal duplo (TOST) como uma abordagem alternativa na comparação do perfil de dissolução de formas farmacêuticas de liberação prolongada. Os perfis de dissolução de comprimidos de liberação prolongada de oxicodona contendo $10 \mathrm{mg}, 20 \mathrm{mg}$ e $40 \mathrm{mg}$ (genérico e referência) foram avaliados de acordo com os requisitos descritos na Farmacopeia Americana. Estes perfis de dissolução foram comparados empregando-se o fator de semelhança convencional (f2) e o método TOST como teste de equivalência. TOST é uma abordagem simples e alternativa para a comparação de perfis de dissolução de formas farmacêuticas de liberação prolongada. Este permite identificar o ponto (ou pontos) que não apresentou semelhança. Considerando-se $\Delta=10$, concluímos que o teste uni-caudal duplo num nível de significância de $5 \%$ apresenta resultados comparáveis àqueles obtidos com o fator de semelhança convencional (f2).

Unitermos: Perfil de dissolução. Comprimidos de liberação prolongada. Fator de semelhança. Test uni-caudal duplo. Teste de equivalência.

\section{INTRODUCTION}

The absorption of a solid dosage form after oral administration depends on three factors: the release of the substance taken, the dissolution of the drug under physiological conditions and the permeability across the gastrointestinal tract. Due to the critical nature of the first two of these steps, an in vitro dissolution may be relevant to the prediction of an in vivo performance (Amidon et al.,

*Correspondence: F. R. Lourenço. Universidade de São Paulo. Av. Prof. Lineu Prestes, 580 - Bloco 13a , 05508-900 - São Paulo - SP, Brasil. Phone: 55-113091-2218; Fax: 55-11-3091-3626. E-mail: feliperl@usp.br
1995; FDA, 1997; Siewert et al.; 2003).

Dissolution studies can, among other useful purposes, be used as tools in the control of quality to demonstrate consistency in manufacture as well as similarity between different products/formulations. The dissolution profile comparison may be carried out using model independent or model dependent methods (EMEA, 2001).

An extended-release dosage form requires at least three test time points to characterize the in vitro drug release profile. An early time point, usually consisting of 1 to 2 hours, is used to show that there is little probability of dose dumping; an intermediate time point is chosen 
to define the in vitro release profile of the dosage form; a final time point is related to the complete release of the drug. Test times and specifications are usually established taking the evaluation of drug release profile data as a basis (USP 35, 2012a).

A simple model independent approach used a difference factor (f1) and a similarity factor (f2) to compare dissolution profiles (Moore, Flanner, 1996). The difference factor (f1) calculates the percentage (\%) of difference between the two curves at each time point, there being a measurement of relative error between the two curves. The similarity factor (f2) is a logarithmic reciprocal square root transformation of the sum of squared error and works as a measurement of the similarity in the dissolution percentage between the two curves (FDA, 1997).

This model independent method becomes the most suitable for dissolution profile comparison when the following recommendations are taken into account: (a) five or more dissolution time points must be available; (b) dissolution measurements of the test and reference batches must be made under the same conditions; (c) only one measurement must be considered after an $85 \%$ dissolution of both products; (d) the use of a mean will only be possible if the relative standard deviation (RSD) at the earlier time points is not superior to $20 \%$ and to $10 \%$ at other time points (FDA, 1997; O'Hara et al., 1998; Shah et al., 1998). An f2 value between 50 and 100 generally suggests similarity between the two dissolution profiles.

Studies carried out by several researchers demonstrated that the similarity factor (f2) is a useful tool to confirm similarity between two dissolution profiles. However, according to our practical experience, similarity factor $\mathrm{f} 2$ does not allow point-to-point comparison, occasionally not showing which time-point (or timepoints) is not similar. These limitations are critical, particularly regarding extended-release dosage forms.

The aim of this work is to present the two onesided test (TOST) as an alternative approach to compare dissolution profiles of extended-release dosage forms. Similarity factor $\mathrm{f} 2$ and two one-sided test (TOST) were compared, taking the results of dissolution profiles of oxycodone extended-release tablets as a basis. The two one-sided test has been employed in the assessment of pharmaceutical equivalence (Lourenço, Pinto, 2012).

\section{MATERIAL AND METHODS}

\section{Extended-Release Tablets and Reference Standard}

Oxycodone extended-release tablets of $10 \mathrm{mg}, 20$ $\mathrm{mg}$ and $40 \mathrm{mg}$ (reference and generic) were purchased from Brazilian suppliers. Oxycodone hydrochloride reference standard (Batch: KOG276, Potency: 99.6\%) was provided by United States Pharmacopeia.

\section{Instrumentation}

The dissolution tests were conducted using a VanKel system (VanKel VK 7010)-comprising a bath with six vessels-and meeting the physical and mechanical specifications required by the USP chapter $<711>$ (USP $35,2012 b)$. The instrument was mechanically calibrated using a paddle and baskets, according to the USP requirements. An Agilent liquid chromatograph (Agilent 1200 Series) equipped with a binary pump, auto-sampler and UV variable wavelength detector was employed in the quantifications of dissolved oxycodone.

\section{Dissolution test}

The tests were conducted using $900 \mathrm{~mL}$ of simulated gastric fluid (without enzymes) maintained at $37.0 \pm 0.5^{\circ} \mathrm{C}$, using USP baskets at a rotation speed of $100 \mathrm{rpm}$. Aliquots of dissolution medium were withdrawn after 1, 2, 4, 8 and 12 hours of dissolution. Samples were filtered using $0.45 \mu \mathrm{m}$ syringe filters, being their oxycodone content then analyzed by liquid chromatography.

The liquid chromatograph was equipped with a $230 \mathrm{~nm}$ detector and a $3.9 \mathrm{~mm} \times 30 \mathrm{~cm}$ column containing $10 \mu \mathrm{m}$ packing $\mathrm{L} 1$. It was maintained at a temperature of $60^{\circ} \mathrm{C}$ with a flow rate of about $1.0 \mathrm{~mL}$ per minute. Aliquots of $50 \mu \mathrm{L}$ of oxycodone reference standard and sample solutions were injected into the chromatograph, having the amounts of dissolved oxycodone been calculated taking the areas obtained in the chromatograms as a basis (USP $35,2012 \mathrm{c})$.

\section{Statistical analysis}

The two one-sided test was employed as an equivalence test to compare the results of the dissolution profiles of reference generic products. Equivalence was tested by the determination of $90 \%$ confidence intervals $(90 \% \mathrm{CI})$ based on the standard deviations obtained from the results of each time-point of the dissolution profiles. In this two one-sided test, we considered $\alpha=0.05$. We rejected the null hypothesis and declared the dissolution profiles similar (or equivalent) when the $90 \%$ CI for the difference was completely contained in the defined range that was considered to be scientifically trivial $( \pm \Delta)$. We considered that an appropriate range to equivalence testing should be defined taking the specifications of the 
TABLE I - Dissolution results of oxycodone extended-release tablets

\begin{tabular}{lcccc}
\hline $\begin{array}{l}\text { Dose } \\
(\mathrm{mg})\end{array}$ & $\begin{array}{c}\text { Time } \\
(\mathrm{h})\end{array}$ & $\begin{array}{c}\text { Acceptance Criteria } \\
(\%)\end{array}$ & $\begin{array}{c}\text { Generic } \\
\text { Mean }(\%)(\text { RSD } \%)\end{array}$ & $\begin{array}{c}\text { Reference } \\
\text { Mean }(\%) \text { (RSD \%) }\end{array}$ \\
\hline 40 & 1 & $37-57$ & $45.5(2.8)$ & $45.6(3.3)$ \\
& 2 & --- & $60.1(2.9)$ & $59.8(3.1)$ \\
& 4 & $68-88$ & $77.1(3.2)$ & $76.2(2.6)$ \\
& 8 & --- & $94.6(3.5)$ & $92.9(1.7)$ \\
& 12 & NLT 85 & $101.0(3.4)$ & $98.7(1.3)$ \\
\hline 20 & $33-53$ & $44.1(1.4)$ & $45.8(1.7)$ \\
& 1 & --- & $57.8(1.5)$ & $59.7(1.5)$ \\
& 2 & $63-83$ & $74.4(1.6)$ & $76.7(1.5)$ \\
& 4 & --- & $93.4(2.0)$ & $94.8(1.2)$ \\
& 8 & NLT 85 & $102.9(2.6)$ & $101.0(1.1)$ \\
\hline 10 & $29-49$ & $39.5(1.1 \%)$ & $38.7(1.5)$ \\
& 12 & --- & $51.6(1.4)$ & $65.8(1.7)$ \\
& 1 & $58-78$ & $66.4(1.4)$ & $83.1(1.4)$ \\
& 2 & --- & $84.0(1.1)$ & $91.7(1.8)$ \\
\hline
\end{tabular}

NLT: Not less than

dissolution test of extended-release dosage forms as a basis.

\section{RESULTS AND DISCUSSION}

The dissolution profile of oxycodone extendedrelease tablets containing $40 \mathrm{mg}, 20 \mathrm{mg}$ and $10 \mathrm{mg}$ is shown in Figure 1. All the evaluated products comply with the acceptance criteria-shown in Table I-described in the United States Pharmacopeia (USP 35).

The two one-sided equivalence test showed that in all time-points evaluated the generic and reference

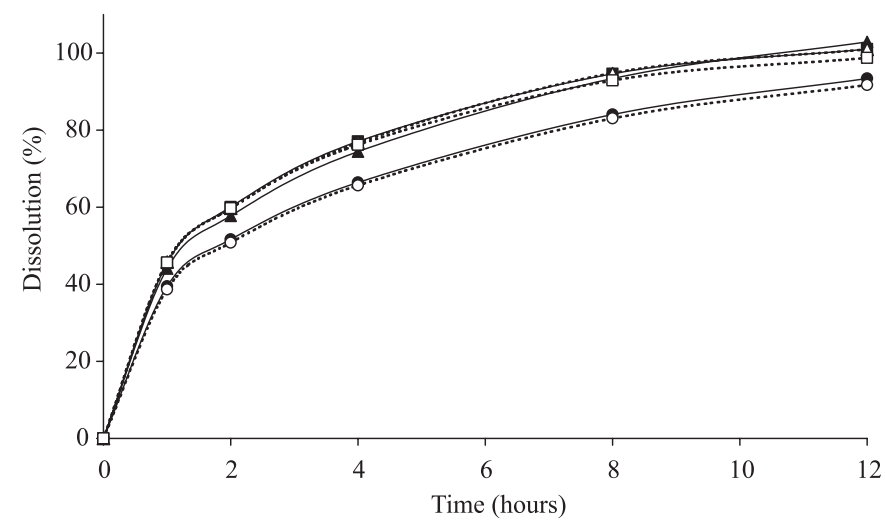

FIGURE 1 - Dissolution profiles for generic $10 \mathrm{mg}(\bullet)$, generic $20 \mathrm{mg}(\boldsymbol{\square})$, generic $40 \mathrm{mg}(\mathbf{\Delta})$, reference $10 \mathrm{mg}(\bigcirc)$, reference $20 \mathrm{mg}(\square)$ and reference $40 \mathrm{mg}(\triangle)$ products. products were found similar (Figure 2). According to the comparison results among doses, the two one-sided test showed that for some point-times there is not similarity (Figure 3). In the comparison between $10 \mathrm{mg}$ and $40 \mathrm{mg}$ generics we verified that the dissolution rates were not similar in 4 and 8hours. The same happened in the pointtimes of 8 and 12 hours when comparing $10 \mathrm{mg}$ and $20 \mathrm{mg}$ generics. These results are in accordance with the similarity factor (f2) obtained in each comparison, as shown in Table II.

The similarity factors (f2) obtained for the comparisons between generic $10 \mathrm{mg}$ and generic $20 \mathrm{mg}$ and between generic $10 \mathrm{mg}$ and generic $40 \mathrm{mg}$ reached a score above 52.6 and 55.3, respectively. In spite of this, these values were significantly lower than those obtained in the other comparisons, what might be a hint that the two one-sided test (TOST) is more rigorous (conservative) than the similarity factor (f2).

The two one-sided test (TOST) allowed us to identify the time-point (or time-points) that did not show similarity, what may help in the development of new products. This information is mistaken in the conventional similarity factor (f2) approach. One of the most important issues regarding the two one-sided test (TOST) is the definition of $\Delta$. This acceptance criteria $( \pm \Delta)$ is the limit beyond which the difference in mean values should be considered scientifically significant. Its definition requires prior knowledge as well as its intended application. We 
(a)

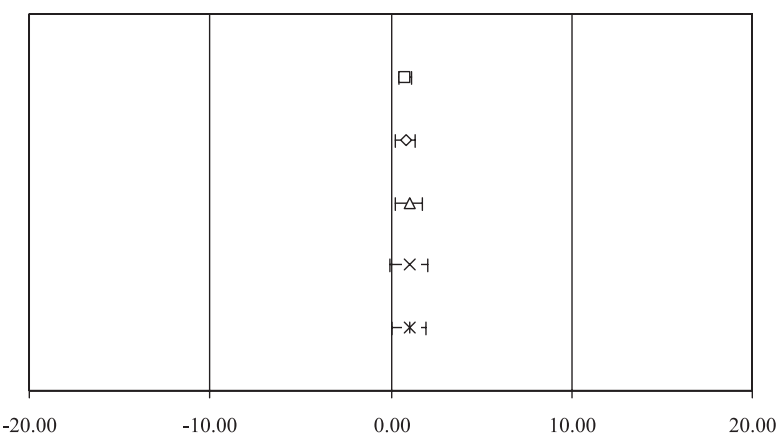

(b)

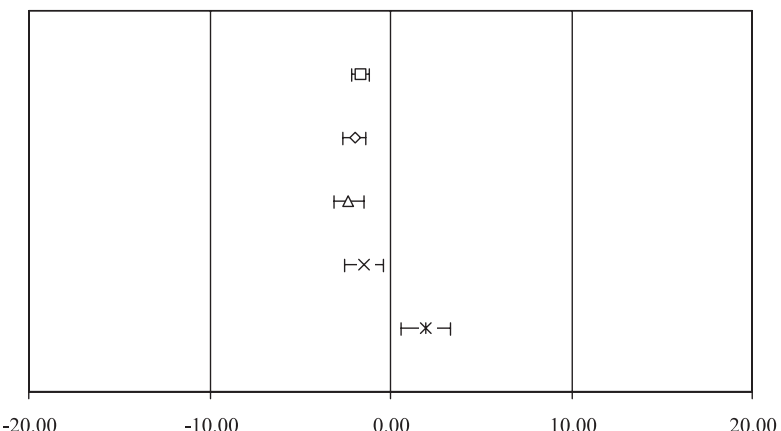

(c)

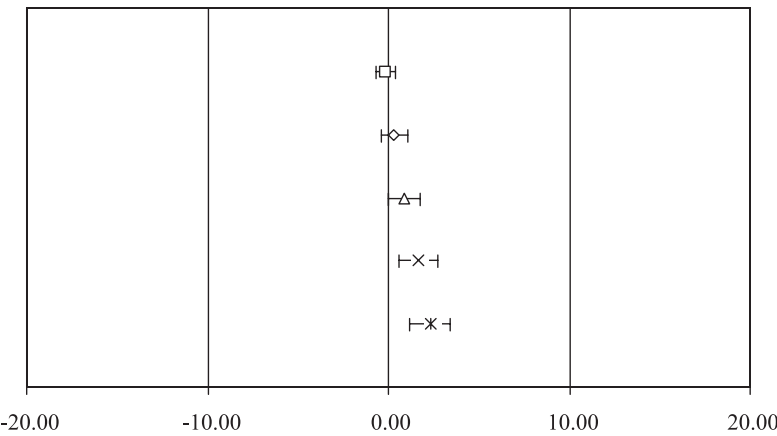

FIGURE 2- Equivalence test (two one-sided test) for dissolution profiles of $10 \mathrm{mg}$ generic versus reference $10 \mathrm{mg}$ (a), $20 \mathrm{mg}$ generic versus reference $20 \mathrm{mg}$ (b) and $40 \mathrm{mg}$ generic versus reference $40 \mathrm{mg}$ (c). Dissolution time-point of $1(\square), 2(\diamond)$, $4(\triangle), 8(\times)$ and 12 hours $(*)$. (a)

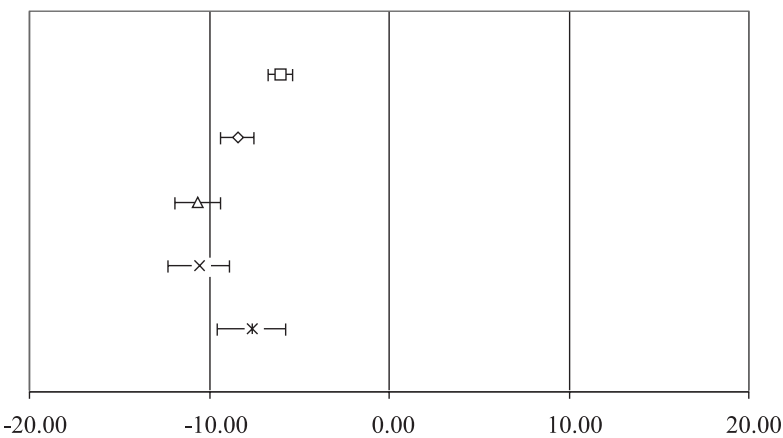

(b)

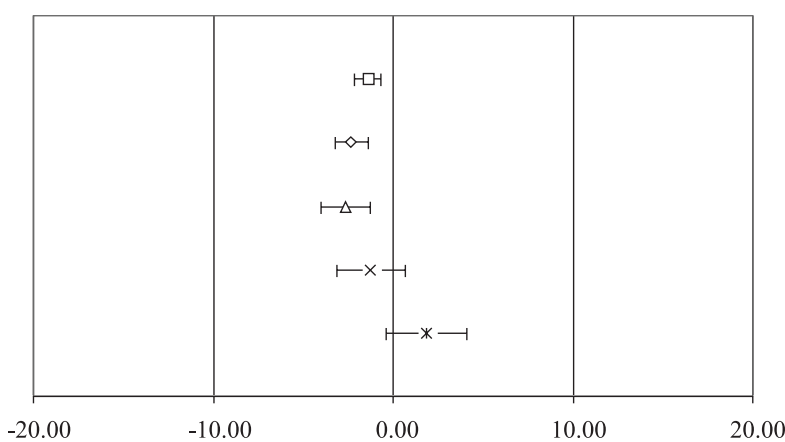

(c)

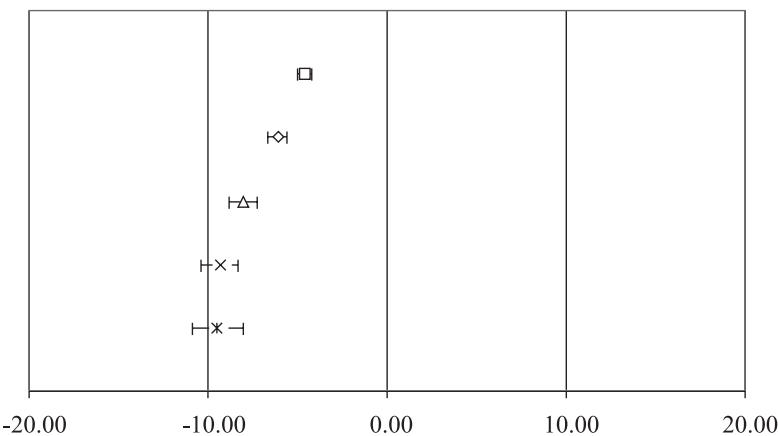

FIGURE 3 - Equivalence test (two one-sided test) for dissolution profiles of $10 \mathrm{mg}$ generic versus $40 \mathrm{mg}$ generic (a), $20 \mathrm{mg}$ generic versus $40 \mathrm{mg}$ generic (b) and $10 \mathrm{mg}$ generic versus 20 mg generic (c). Dissolution time-point of $1(\square), 2(\diamond), 4(\triangle)$, $8(\times)$ and 12 hours $(*)$.

TABLE II - Results of similarity factor (f2) and two one-sided test (TOST) for dissolution profile comparison of oxycodone extendedrelease tablets

\begin{tabular}{lcc}
\hline Comparisons & Similarity factor $(f 2)$ & Two one-sided test (TOST) \\
\hline Generic $10 \mathrm{mg}$ vs Reference $10 \mathrm{mg}$ & 91.8 & Similar \\
Generic $20 \mathrm{mg}$ vs Reference $20 \mathrm{mg}$ & 83.5 & Similar \\
Generic $40 \mathrm{mg}$ vs Reference $40 \mathrm{mg}$ & 88.8 & Similar \\
Generic $10 \mathrm{mg} v s$ Generic $40 \mathrm{mg}$ & 52.6 & Not similar* \\
Generic $20 \mathrm{mg}$ vs Generic $40 \mathrm{mg}$ & 82.9 & Similar \\
Generic $10 \mathrm{mg} v s$ Generic $20 \mathrm{mg}$ & 55.3 & Not similar** \\
\hline
\end{tabular}

*No similarity in 4 and 8 hours for $\Delta=10$. **No similarity in 8 and 12 hours for $\Delta=10$. 
defined $\Delta=10$ as an appropriate range to equivalence testing, based on the specifications of the dissolution test of extended-release dosage forms.

\section{CONCLUSION}

The two one - sided equivalency test (TOST) is a simple and alternative approach to compare dissolution profiles of extended-release dosage forms. It allows us to identify the time-point (or time-points) that did not show similarity. We concluded that the two one-sided test performed at a significance level of 5\% and defined as $\Delta=10$ presents results comparable to those obtained by the conventional similarity factor (f2).

\section{REFERENCES}

AMIDON, G.L.; LENNERNAS, H.; SHAH, V.P.; CRISON, J.R. A theoretical basis for a biopharmaceutic drug classification: the correlation of in vitro drug product dissolution and In Vivo Bioavailability. Pharm. Res., v.12, p.413-420, 1995.

EMEA. European Medicines Agency. Note for guidance on the investigation of bioavailability and bioequivalence. London: European Medicines Agency, 2001. v. 1, 18p.

FDA. Food and Drug Administration. Guidance for industry: dissolution testing of immediate release solid oral dosage forms. Rockville: Food and Drug Administration, 1997. v. $1,11 \mathrm{p}$.

LOURENÇO, F.R.; PINTO, T.J.A. Assessment of pharmaceutical equivalence: difference test or equivalence test? Lat. Am. J. Pharm., v.31, n.4, p.591-604, 2012.
MOORE, J.W.; FLANNER, H.H. Mathematical Comparison of Dissolution Profiles. Pharm. Technol., v.20, p.64-74, 1996.

O'HARA, T.; DUNNE, A.; BUTLER, J.; DEVANE, J. A review of methods used to compare dissolution profile data. Pharm. Sci. Technol. To., v.1, p.214-223, 1998.

SHAH, V.P.; TSONG, Y.; SATHE, P.; LIU, J.P. In vitro dissolution profile comparison - statistics and analysis of the similarity factor, f2. Pharm. Res., v.15, p.889-896, 1998.

SIEWERT, M.; DRESSMAN, J.; BROWN, C.K.; SHAH, V.P. FIP/AAPS guidelines to dissolution/in vitro release testing of novel/special dosage forms. AAPS PharmSciTech, v.4, p.1-10, 2003.

UNITED States Pharmacopeia. $35^{\text {th }}$ ed. The dissolution procedure: development and validation. Rockville: United States Pharmacopeia, 2012a. p. 675-681 USP 35. <1092>

UNITED States Pharmacopeia. $35^{\text {th }}$ ed. Dissolution test. Rockville: United States Pharmacopeia, 2012b. p.295-301. USP 35. <711>

UNITED States Pharmacopeia. $35^{\text {th }}$ ed. Oxycodone hydrochloride extended-release tablets. Rockville: United States Pharmacopeia, 2012c. p.4173-4175. USP 35.

Received for publication on $04^{\text {th }}$ June 2012 Accepted for publication on $23^{\text {th }}$ November 2012 